\title{
DIFFERENT EFFECTIVENESS OF SAFETY MEDIA ON KNOWLEDGE, ATTITUDE, AND SELF-EFFICACY IN DISASTER PREPAREDNESS AMONG VISITORS AT A HOSPITAL
}

\author{
Asteria Narulita Pramana, Yuliani Setyaningsih, M. Zen Rahfiludin \\ Department Occupational Safety and Health, Masters Program in Health Promotion, \\ Faculty of Public Health, Universitas Diponegoro
}

\begin{abstract}
Background: In our current times, to communicate risks effectively with populations, communities, families and individuals is essential for everyone to be better prepared when disaster and crisis hit. The purpose of this study was to determine the different effecttiveness of safety media on knowledge, attitude, and self-efficacy in disaster preparedness among visitors at a hospital.

Subject and Methods: This was a quasi-experiment conducted at a hospital in Semarang. A sample of 33 hospital visitors was selected for this study and divided into three groups: leaflet group, video group, and leaflet-video group. The dependent variables were knowledge, attitude, and self-efficacy in disaster preparedness. The independent variable was safety media. The data were collected by questionnaire. The data were analyzed by Oneway ANOVA and posthoc test.

Results: Mean score of knowledge in the leaflet-video group was higher than the remaining two groups, and it was statistically significant. Differences in mean score of attitude and self-efficacy between the three groups were statistically non-significant.

Conclusion: Leaflet-video is the most effective safety media to improve knowledge in disaster preparedness. Leaflet, video, and its combination do not make difference to change attitude and self-efficacy.
\end{abstract}

Keywords: hospital, media safety, knowledge, attitude and self-efficacy.

\section{Correspondence:}

Asteria Narulita Pramana, Department Occupational Safety and Health, Masters Program in Health Promotion, Faculty of Public Health, Universitas Diponegoro,

Email: asterianarulita@gmail.com. Mobile: 085640808711.

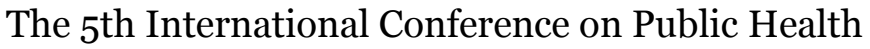
Best Western Premier Hotel, Solo, Indonesia, February 13-14, 2019 | 163 https://doi.org/10.26911/theicph.2019.02.08 